Arteterapia. Papeles de arteterapia y educación para inclusión social ISSN: $1886-6190$

\title{
Arteterapia e infancia. Un ensayo para la vida
}

\author{
Esther Carmona Pastor ${ }^{1}$
}

Recibido: 30 de julio de 2016 / Aceptado: 28 de agosto de 2016

Resumen. Es complejo hablar de trastorno mental grave cuando hablamos de pacientes de tan corta edad.

Casi todos ellos son derivados por el fracaso en un espacio común, la escuela, y es que al enfrentarse a los iguales hace aflorar el conflicto.

Normalmente los problemas son muy complejos que llegan aderezados con dificultades en casa. Es por esto que la intervención se realiza desde un equipo multidisciplinar que aborda no solo al niño sino a su entorno.

El reto está en cómo intervenir con pacientes tan pequeños con un uso escaso del lenguaje verbal.

El espacio de arteterapia se presenta como un espacio de contención seguro donde poder forjar un vínculo estable que nos lleve a explorar y experimentar buscando poder rehacer parte de esa experiencia vital. El lenguaje plástico dará forma a sus emociones, dificultades e inquietudes y también posibilitará la trasformación.

Todo ello se realiza a través del juego, espacio que posibilita un ensayo para la vida.

Palabras clave: Arteterapia; infancia; juego; emoción; vínculo.

\section{[en] Art therapy and childhood. A rehearsal for life}

Abstract. Disscussing serious mental disorder, when we talk about very young patients, is a very complex issue.

Nearly all cases arise by failure in a common space, school. Facing peers brings up conflict to the surface.

Usually these problems are very complex as well as arising with added difficulties at home. That is why any intervention is performed by a multidisciplinary team that addresses not only the children themselves but also their environment.

The challenge lies in how to intervene with such young children with limited use of verbal language. Art therapy is presented as a safe containment space where they can forge a stable relationship that leads us to explore and experience looking to redo part of that life experience. Plastic language will shape their emotions, difficulties and concerns and also enable the transformation to occur.

All this is done through play, which allows a rehearsal for life.

Keywords: Art therapy; childhood; play; emotion; link.

1 Hospital de día San Agustín . Licenciada en Bellas Artes y Arteterapeuta por la UCM. Arteterapeuta del grupo de menores de entre 6 a 9 años del Hospital de día San Agustín de Leganés, centro concertado con la Comunidad de Madrid, desde septiembre del 2012 bajo el marco del convenio entre Argos Arte en Acción y Cogesín sanitaria. Secretaria de Foro iberoamericano de arteterapia (AFIA) y miembro de la Federación Española de Asociaciones Profesionales de Arteterapia (FEAPA).

E-mail:carmona.esther@gmail.com 
Sumario. 1. Un hospital de día psiquiátrico infantil; 2. La familia y la escuela. La amenaza de lo cotidiano; 3 . El proceso de conocimiento; 4 . El juego. El poder de exploración y experimentación; 5. La emoción y el lenguaje; 6 . Conclusiones de la experiencia; 7. Referencias bibliográficas.

Cómo citar: Carmona Pastor, E. (2016) Arteterapia e infancia. Un ensayo para la vida, en Arteterapia. Papeles de arteterapia y educación para inclusión social 11, 267-275.

\section{Un hospital de día psiquiátrico infantil}

Los Hospitales de Día-Centros Centros Educativo Terapéuticos (HdD-CET) se constituyen como un recurso de intervención coordinada de profesionales procedentes de diferentes sectores (educativos y sanitarios) para proporcionar una atención integral al alumnado que manifiesta trastornos psíquicos que se inician en la infancia y en la adolescencia cuya derivación depende de los Centros de Salud Mental (CSM).

La intervención que se expone ha sido desarrollada en un HdD-CET de la Comunidad de Madrid. Se trata de un dispositivo ambulatorio a tiempo parcial para realizar tratamientos intensivos con niños/as con patologías graves que requieren un abordaje integral y multidisciplinar.

El objetivo principal del centro es permitir una "experiencia emocional correctora", que va a implicar la creación de una relación vincular o la modificación de los patrones relacionales previos.

Esta relación permitirá la separación y la individuación y conducirá al surgimiento del mundo simbólico.

El abordaje se realiza desde un equipo multidisciplinar que aborda de forma integral al niño/a. Las familias también son parte de proceso, solo contando con su compromiso se inicia el tratamiento. Con ellos parte del equipo se reúne una vez en semana.

El alta se inicia de manera parcial pues se va integrando al paciente poco a poco en la escuela ya que durante el tiempo que dura el tratamiento los pacientes acuden a la parte educativa con la que cuenta el hospital.

El área de infantil cuenta con un total de 15 pacientes que se divide en tres grupos de edad:

$$
\begin{array}{ll}
\text { - } & \text { Grupo A_entre } 6 \text { y9 años } \\
\text { - } & \text { Grupo B_entre } 9 \text { y } 12 \text { años } \\
\text { - } & \text { Grupo C_entre } 12 \text { y } 14 \text { años }
\end{array}
$$

Cada uno de ellos cuenta con un terapeuta que actúa como figura referente que en palabras de Edith Brokler ${ }^{2}$, se ofrece para permitir la evolución del desarrollo ahí donde se detuvo dando una función de contención emocional, de comprensión y elaboración de conflictos y de reconstrucción.

El centro actúa con un modelo de comunidad terapéutica y los profesionales de área de terapia que intervienen son:

$$
\text { - } 1 \text { psiquiatra }
$$

\footnotetext{
${ }^{2}$ Psicóloga y coordinadora de Hospital de día "San Agustín"
} 
- 2 psicólogos

- 1 terapeuta ocupacional

- 2 psicopedagogos

- 1 DUE

- $\quad 2$ arteterapeutas

El espacio de arteterapia se da una vez en semana y su duración es de una hora. Para posibilitar este espacio en relación con el resto de profesionales se genera un informe previo que indica como han estado los pacientes durante la semana, una reunión con el equipo tras la intervención y una supervisión por parte de todo el equipo de manera trimestral donde se ve el proceso y la evolución de los pacientes.

Los objetivos del arteterapia son:

- - posibilitar una vía de comunicación posibilitando la elaboración de las dificultades y conflictos personales.

- $\quad$-generar un espacio seguro donde poder probar posibilidades de ser.

El trabajo que se expone corresponde con el realizado con los niños y niñas de menor edad, el Grupo A. Este trabajo comenzó en julio del 2012 y actualmente se sigue interviniendo. El número de pacientes tratado en este grupo son 20 y el grupo nunca ha excedido los 5 . Actualmente la intervención se realiza con 5 pacientes.

\section{La familia y la escuela. La amenaza de lo cotidiano.}

Un ámbito donde se debería de encontrar con cuidado y estabilidad es el hogar. La mayoría de estos niños/as no encuentran esto en sus casas y es por eso que la intervención no se centra solo en ellos sino que también sus cuidadores (padres/madres, abuelos/abuelas, educadores/educadoras,...) son objeto de trabajo. Es importante que los cuidadores conozcan el proceso de los niños/as y se acompasen a él. Se mantienen reuniones semanales donde se ven conflictos y se les ayuda con pautas.

Al igual la escuela se presenta como un lugar de fracaso. El sitio donde normalmente comienza este proceso. Este espacio también es intervenido pero en una fase final del tratamiento ya que el niño/a se va incorporando poco a poco a la escuela y de esta manera asegurar que no va a existir un nuevo fracaso ${ }^{3}$.

En muchas ocasiones esto provoca una fuerte división entre cuerpo y mente. Son tantas las experiencias negativas con su entorno que el niño/a decide dividirse y vivir seguro en un mundo de la mente. Allí forja sus escudos, sus defensas y termina por ser inalcanzable.

La casa y la escuela terminan siendo un elemento representado en la obra.

3 En la mayoría de los casos una vez realizada el alta de los pacientes vuelven a contar con un seguimiento del CSM. 

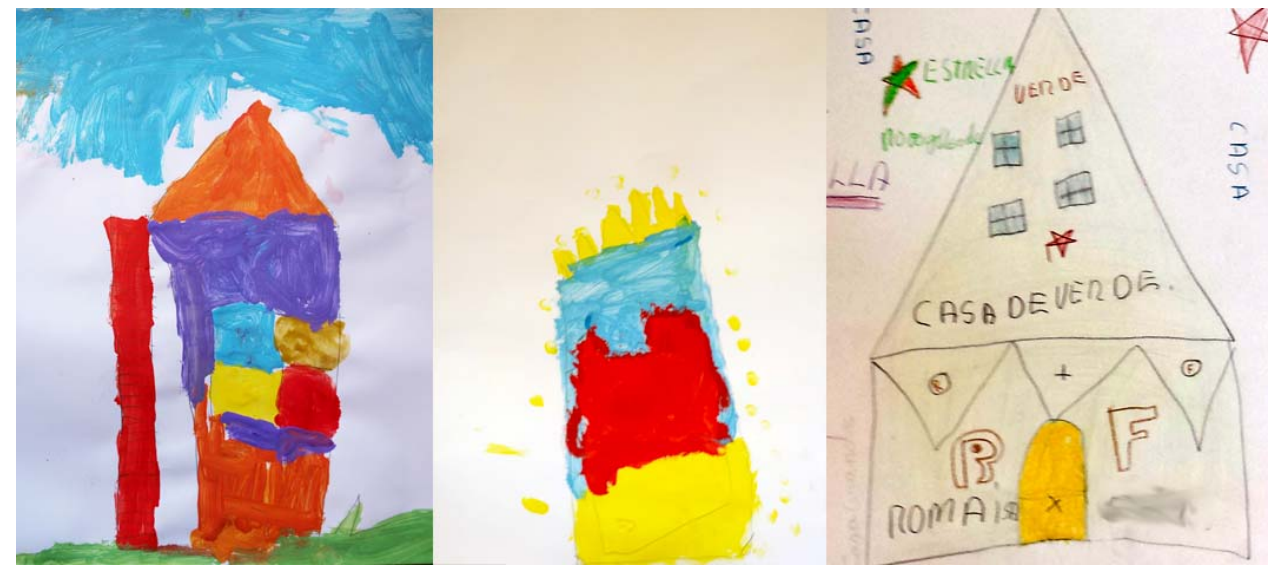

Figura 1. Representación de casa por diferentes pacientes

El "efecto terapéutico del ambiente institucional, la terapia ambiental" implica la utilización de la experiencia de vida global, los abordajes múltiples y la utilización de la institución como instrumento terapéutico al modo de un sistema social en el que todos los miembros (pacientes y equipo terapéutico) se influyen recíprocamente. En suma "un ambiente estructurado con variedad de relaciones humanas, interacciones emocionales satisfactorias, oportunidades para nuevos aprendizajes y experiencias, manejo de situaciones nuevas y el desarrollo de competencias personales y sociales" (Bloker E, 2010). En esto basamos lo que llamamos una "experiencia terapéutica correctora" Por tanto el aula se plantea como una nueva posibilidad de "construcción familiar o social" generando nuevas maneras de ser fuera y dentro.

La obra se transforma según se posibilitan nuevas experiencias.

\section{El proceso de conocimiento.}

En la etapa inicial lo que se intenta es conseguir forjar un vínculo estable. Es durante esta etapa don de el niño/a despliega todo su abanico de defensas. A través del dibujo nos muestra todas sus armas. Dinosaurios, dientes, espadas,... son sus armas y miles de ojos nos muestran que están en alerta, que nos miden y observan. Poco a poco este despliegue va desapareciendo y nos acerca a su mundo de la mente. Solo nos deja observar, aun no podemos penetrar. Según pasa el tiempo y va comprobando que el espacio es seguro se va abriendo hasta que ya se puede entrar.

Es este momento cuando se puede hablar de un vínculo solido y cuando se puede comenzar a hacer un trabajo en profundidad. 


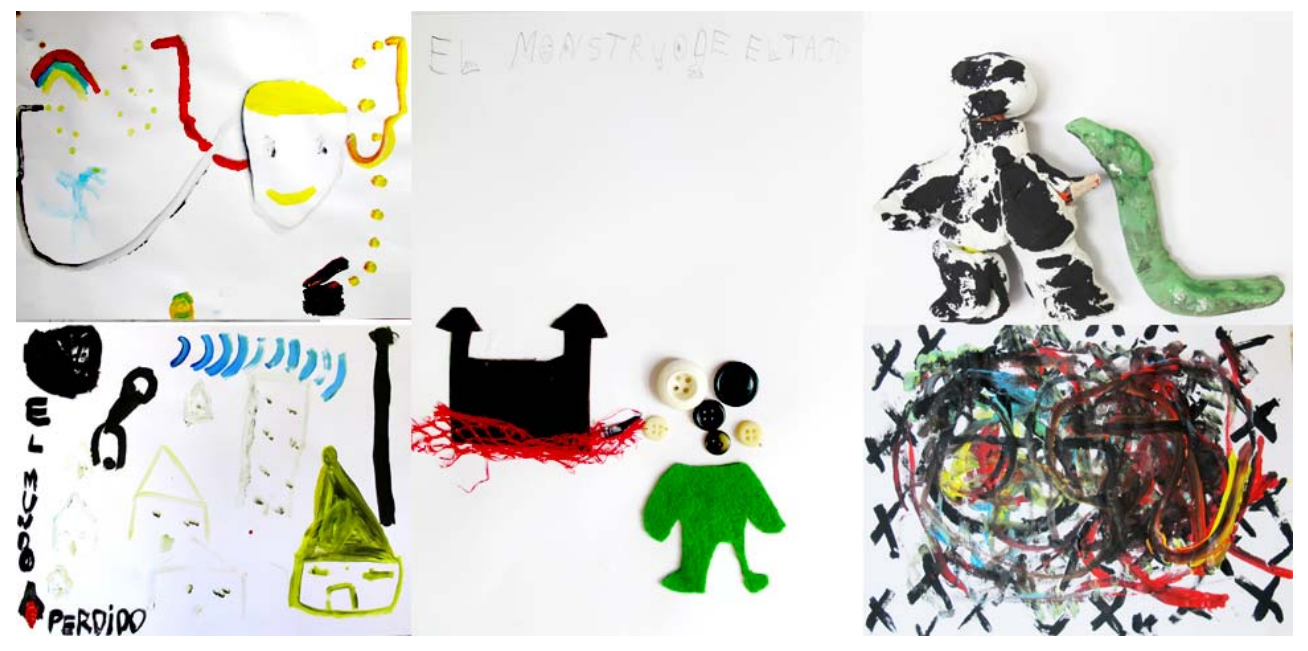

Figura 2 Imágenes pertenecientes al proceso de un paciente.

No se puede hablar de un tiempo concreto, cada proceso y paciente tienen el suyo.

Este recorrido solo lo da el tiempo y la estabilidad. El mostrarse solido generando un espacio de libertad y seguridad es la clave para poder llegar a ellos. Los momentos iniciales son los más complejos. Son los momentos en los que a pesar de la contención, en ocasiones el paciente no pueden sostenerse y explota, pero poco a poco se van sintiendo seguros y entrando en el trabajo. Estas explosiones físicas se trasladan al papel donde pueden ser trabajadas. Y es aquí en el espacio físico de la obra donde nos empiezan a mostrar sus avances y retrocesos. Y esto comienza a poseer un lenguaje propio. Ahora a cada forma le acompaña una palabra que la define y según vamos descubriendo la obra vamos conociendo a nuestro paciente.

En ocasiones, en la revisión de los trabajos ellos mismos les cuesta reconocerse en el inicio o recordar situaciones que ya llegados a ese punto, les avergüenzan pero este trabajo es necesario, han de ser plenamente conscientes de su proceso y evolución, es nuestra obligación el mostrarles una panorámica del recorrido.

La relación con los iguales es algo fundamental pues el compañero actúa como un espejo. En el otro puede ver lo que no le gusta de sí mismo. A esto le suelen responder con un fuerte rechazo pero el trabajo lleva a esa revisión de conductas y asimilar las situaciones que nos gustan. De esta manera las conductas no se aprenden sin más, sino que son observadas, examinadas, probadas e interiorizadas. Los que un día fueron nuevos se transforman en veteranos y enseñan a los demás su propia experiencia. Entender el propio proceso como algo positivo, tan importante que ha de ser mostrado y ofrecido a los demás empoderándoles. 


\section{El juego. El poder de exploración y experimentación}

Debido a muchos factores pero principalmente al miedo estos niños/as no tienen una relación sana con el entorno al que ven como una amenaza. Una mala experiencia, el fracaso, los intentos fallidos,... son guardados en su memoria e impiden el poder explorar y generar nuevas relaciones con el espacio o entorno.

Es por esto que parte de la intervención se centra en el trabajo de exploración. A través del juego reescribimos esta relación. Generamos una exploración donde disfrutamos pudiendo así generar nuevos conocimientos o reescribimos los anteriores y que estos inviten a seguir conociendo y disfrutando.

El juego plantea la posibilidad de ensayar, de generar un espacio de libertad, a pesar de las reglas, donde cada uno puede ser lo que quiera.

Un espacio donde cuerpo y mente están unidos creando sensaciones y nuevos conocimientos en este caso positivos.

El juego nos deja acercarnos a ellos sin vernos como una amenaza. Así reescribimos la relación con el adulto.

A través del juego las reglas y los límites son asumidos de una manera natural.

En el juego las cosas pueden adquirir diversas funciones y es importante que los sentidos se incorporen en su totalidad. Podemos jugar en diferentes espacios, con comida, explorar emociones,... Solo a través de juego el niño/a aprende.

El juego les permite ser quienes quieran ser por tanto probar.

La sensación, emoción y empatía es lo que perseguimos y todo ello bajo una perspectiva divertida y constructiva.

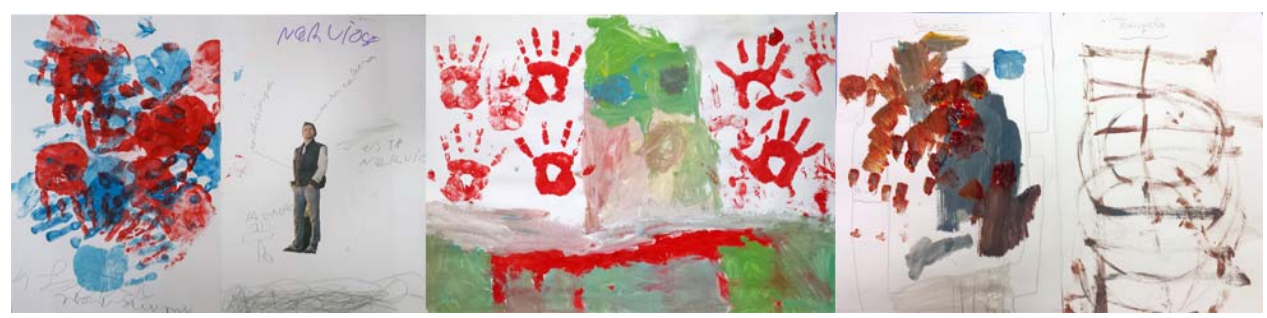

Figura 3.

Para nuestros pequeños pacientes la creación se transforma en juego y como decía Fiorini:

"En este tiempo de creación, el límite entre lo posible y lo imposible es vago, borroso, uno puede precipitarse en lo imposible. Pero si el sujeto insiste, continúa su búsqueda; en algún momento nuevas formas pueden surgir, aparecen nuevos objetos, y esos nuevos objetos habrán realizado la experiencia de arribo al espacio de lo posible”. (Fiorini, 2007)

\section{La emoción y el lenguaje.}

Con niños/as tan pequeños el lenguaje verbal pasa a estar en un segundo plano. Una de las mayores dificultades es que no saben poner palabras a todo aquello que sienten por esto es tan importante el lenguaje plástico. A través de las formas y los 
colores intentamos averiguar que le sucede al cuerpo. Intentamos situar las emociones y los momentos donde estas aparecen. Reelaboramos la experiencia emocional.

Suelen estar muy instalados en lo polar e intentamos explorar toda esa zona media que es donde suelen suceder las cosas. Huimos del bien/mal, de lo malo/bueno, del contento/triste, ... y pasamos a dar matices a los momentos, a las emociones. También vamos dando forma y situándolo en el cuerpo. De esta manera potenciamos esa unión entre cuerpo y mente.

Poco a poco la obra comienza a tomar matices y formas inesperadas. Es entonces cuando pasamos a una exploración más personal. Comenzamos a hablar de lo propio y comenzamos a trabajar en un proceso de exploración de símbolos personales. Potenciamos el desarrollo de la capacidad simbólica de modo que le permitan mantener y satisfacer su deseo de conocer, descubrir y explorar" (Albamonte, 1991)

Poco a poco y de forma automática las cosas van nombrándose y haciéndose concretas. $\mathrm{Y}$ es justo ese el proceso que buscamos, pasar de lo abstracto a lo concreto.

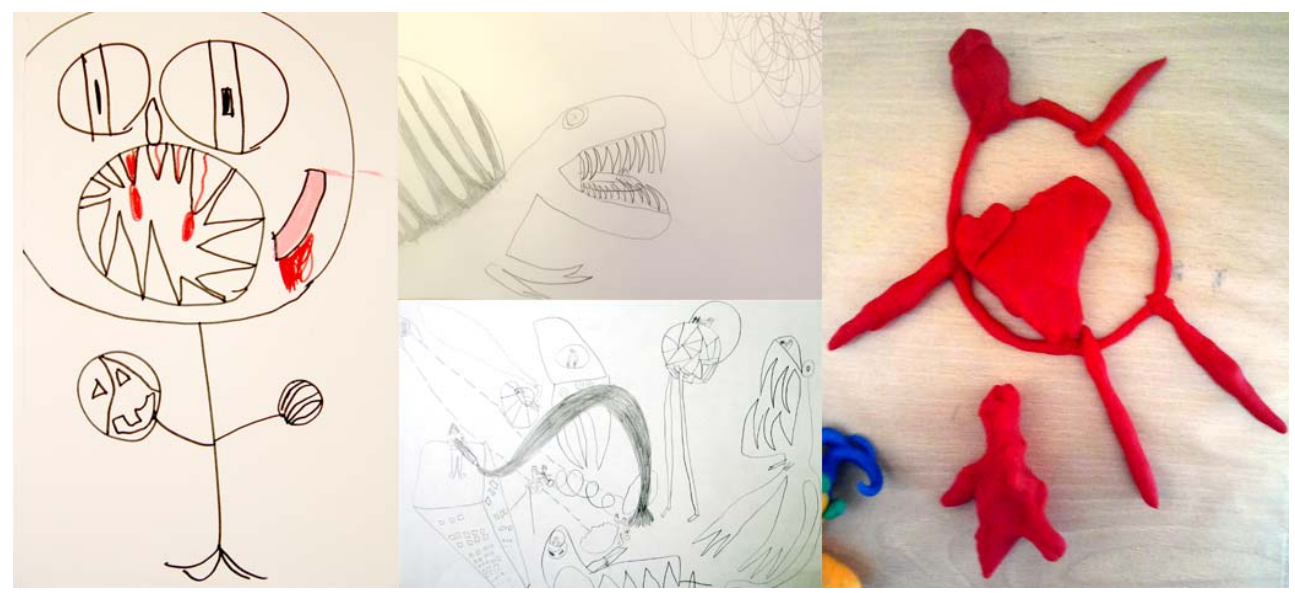

Figura 4. Diferentes trabajos de emociones

\section{Concusiones de la experiencia}

Son cuatro años volando juntos. Veinte pacientes de los cuales dieciséis ya están de alta.

Muchos momentos donde descubrir y aprender juntos, pues cada niño/niña es un mundo y con él hay que redescubrir la intervención. La experiencia te da claves pero no la solución.

Han sido cuatro años que me han enseñado a no sentirme salvadora de nadie, a entender y ver sin retorcerme de rabia que la vida puede ser muy dura desde el principio. A comprender que la profesionalidad es ajustarte durante un espacio/tiempo a tu paciente y a seguir con la vida cuando estés fuera. 
A atenderme y entenderme, pues la ayuda pasa por ser ayudada y para esto está la supervisión que tanto ayudó a poder ampliar mi visión.

Dejándome aparte, la infancia marca toda la vida y un mal tratamiento ayudará a que el futuro tenga un enfermo más. Una vida puede quedar sesgada nada más nacer y en esto no solo tiene que ver la enfermedad, pues a veces la enfermedad no viene dada sino que se genera, se crea.

Solo en un entorno cuidado y seguro puede crecer un niño/a sano.

Esta es la clave, la única. Nosotros podemos intervenir, explorar, jugar,... pero necesitamos que su entorno se convierta en un lugar cuidado y seguro, si no, nada habrá servido.

No quiero concluir la exposición dando una idea fatalista tan solo mostrar la importancia de intervenir con el entorno cuando se trata de infancia. Pero un buen trabajo pasa por asegurarse de que el lugar donde va a crecer ese niño/a es el apropiado.

De aquí la importancia de un trabajo interdisciplinar donde los diferentes profesionales se coordinen para que esa intervención se convierta en algo global. Mientras el arteterapia se muestra perfecto para el trabajo con los pacientes el resto de profesionales intervienen en dar esa seguridad en el hogar.

No a las catorce altas se han podido asegurar que vivirán en un lugar seguro pero si a la mayoría de ellos.

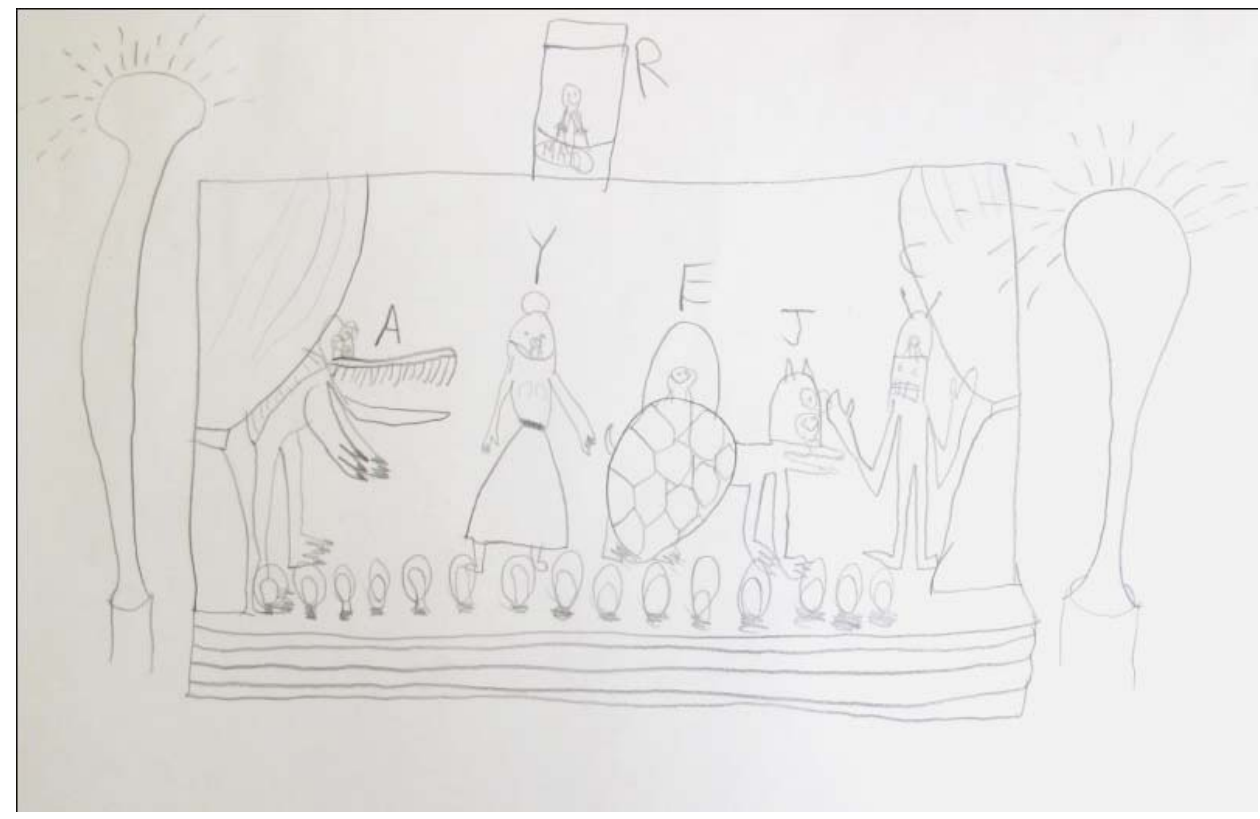

Figura 5. "Retrato del grupo" 


\section{Referencias bibliográficas}

Albamonte M. A., Bermejo V., Ferrándiz C., Guijarro F., Montes I., Palop M. D. Y Sánchez M. (1991) La importancia de la simbolización en los procesos de aprendizaje. Cuadernos de psiquiatría y psicoterapia del niño y del adolescente, Revista 11-12, 109135

Alcamí Pertejo, M. (2010). Un modelo de hospital de día en niños pequeños.

Sus indicaciones y contraindicaciones. Cuadernos de psiquiatría y psicoterapia del niño y del adolescente, Revista 50, 209-223.

http://www.sepypna.com/documentos/articulos/albamonte-importancia-simbolizacion.pdf

Beà, N., Torras, E. (1994) El desarrollo de la identidad en el tratamiento de niños pequeños. Comunicación presentada en el VIII Congreso Nacional de la Sociedad Española de Psiquiatría y Psicoterapia del Niño y del Adolescente.

Bokler, E. (2010). Modelo de intervención terapéutico en el hospital de día de Leganés: Propuestas y reflexiones sobre el trabajo interdisciplinar. Cuadernos de psiquiatría y psicoterapia del niño y del adolescente, Revista 50, 197-207.

Fiorini, H. J. (2007). El psiquismo creador. Vitoria-Gasteiz, España: Agruparte.

Gonzalo Marrodán, J.L. (2010) La relación terapéutica y el trabajo de reconstrucción de la historia de vida en el tratamiento psicoterapéutico de los niños crónicamente traumatizados. Cuadernos de psiquiatría y psicoterapia del niño y del adolescente; 49, 187-204

Klein, M (1930) "Importancia de la formación de símbolos en el desarrollo del yo". Editorial Paidós.

Meltzer, D. (1981) "Sobre el Símbolo”. Símbolo y formación del símbolo. Quadernos di Psicoterapia infantile $n^{\circ}$ 5. Diretti da Carlo Brutti e Francesco Scotti. Edit, Borla Roma.

Winnicott, D. W. (1997) “Realidad y Juego". Editorial Gedisa. 